\title{
Creación de recursos didácticos personalizados en el aula de infantil a través de herramientas TIC
}


El objetivo de esta comunicación es presentar un material didáctico novedoso utilizando las TIC. Este material se propone como forma lúdica de trabajo con el alumnado de Educación Infantil, complementario a metodologías más tradicionales.

Se pretende concienciar a la población de la importancia del uso de las TIC en la educación, dando una visión global sobre la trayectoria de estas en las aulas durante los últimos años, remarcando las ventajas e inconvenientes de su utilización y dando a conocer algunas de las más utilizadas en España. A su vez, se desea reforzar la visión del profesorado como profesional implicado en la elaboración personalizada de materiales y recursos didácticos.

En concreto se va a reforzar el aprendizaje de contenidos de la Unidad Didáctica "L'Univers" por medio de la tablet y la aplicación "Make it". Los resultados de la experiencia indican una alta satisfacción del alumnado con dicha metodología, así como la adquisición de los objetivos propuestos para dicha unidad didáctica. Este trabajo es una pequeña muestra de las múltiples posibilidades que ofrecen las TIC en el ámbito de la educación.

Palabras clave: TIC, tablet, educación, recursos interactivos, materiales propios, innovación.

\section{Introducción}

Nos encontramos en el S.XXI, era de las comunicaciones y las tecnologías de la información (TIC en adelante), donde estas son cada vez más esenciales en la sociedad, el trabajo, ocio y también en la educación. Estas nuevas herramientas no pretenden desplazar las utilizadas tradicionalmente, sino complementar y ayudar a que la educación de los alumnos sea mejor, desarrollando sus fortalezas y mejorando sus debilidades de aprendizaje.

Debido a diversos estudios como el de la UAB (Universitat Autònoma de Barcelona), Blanquerna (Universitat Ramon Llull), el CETEI (Fundació Joan XXIII) que demuestran el potencial de las nuevas tecnologías en la enseñanza y gracias a la aparición de autores mediáticos como Ken Robinson, Eduard Punset, y otros conferenciantes de la organización TED (Tecnología, Entretenimiento y Diseño) TED Conferences y TED Talks, como Ali Carr-Chellman; hoy en día se considera imprescindible el uso de las TIC en la educación infantil y primaria, ya que actualmente los alumnos y alumnas están rodeados de estas herramientas, formando parte de su vida cotidiana.

Se podría definir a los alumnos actuales como nativos digitales (Marchal, 2010), lo cual indica que dominan con facilidad los medios digitales a la vez que aprenden en y de la red, así como valoran positivamente el mundo digital. Es por ello que los docentes deben brindarles la oportunidad de que las conozcan y aprendan a darles un uso 
adecuado desde la infancia, mostrándoles su utilidad pedagógica y aprovechando el factor lúdico y motivador de estas.

Una de las ventajas del uso de las TIC en el aula es el desarrollo de la creatividad del alumnado. Según Marqués (2008) respecto a la PDI (Pizarra Digital Interactiva) «Las clases resultan más dinámicas y motivadoras al salir el profesor y alumnos a interactuar directamente con el puntero: inmediatez, más autonomía y creatividad.»

Robinson (2013) afirma que la creatividad es el proceso por el que se tienen ideas originales que tienen valor. Tal y como afirma este autor, las nuevas tecnologías pueden ayudar a mejorar la creatividad y talento de las personas.

Cabe destacar que el uso de este tipo de herramientas da lugar a la motivación de los alumnos y alumnas, haciendo que éstos estén más dispuestos a la recepción de conocimientos, y dediquen más tiempo a aprender, generando el aprendizaje por medio de actividades y juegos lúdicos. Sin dejar de lado los libros de texto, se acoplan e incluyen actividades digitales a los distintos temarios educativos, lo cual está teniendo una gran aceptación en las aulas.

Además, el uso de las TIC fomenta la autonomía del alumnado, dándole un papel activo, lo cual es fundamental para su total formación (Esteve, 2009). Esta autonomía es beneficiosa para aquellos que poseen necesidades educativas especiales o un ritmo de aprendizaje más lento al de la clase. Debido a la existencia de actividades interactivas con distintos niveles de jugabilidad, cada alumno puede ir a su ritmo, progresando poco a poco, y haciendo hincapié en aquellos conceptos que no posee tanta habilidad para así mejorarlos en un futuro.

Pero no todo son ventajas ante la inclusión de las nuevas tecnologías en la educación. Éstas generan inseguridad e incertidumbre en el profesorado, ya que muchos de ellos no tienen la formación suficiente para poner en práctica dichos recursos en el aula. Debido a esto se está poniendo en marcha, en los CEFIRES, cursos de formación TIC y reciclaje para docentes. Aún así, es cierto que el profesor debe renovar constantemente su formación en las nuevas tecnologías, ya que éstas están en constante cambio; además de dedicar, en ocasiones, tiempo extra para este aprendizaje o búsqueda de materiales innovadores que se desee implantar en el aula (Laz, 2011).

Aún existiendo ventajas e inconvenientes, en España se ha apostado por el uso de las TIC mediante el Plan Avanza (2006-2010) y ahora el Plan Avanza2 (2011-2015).

Tras aprobar la LOE en el año 2006, y de acuerdo con la LOMCE, se produce la aparición de un nuevo currículo que incorpora las competencias básicas a la educación, donde una de ellas es la competencia en el tratamiento de la información y competencia digital. Se ha constatado que aquellos centros que incorporaron estas nuevas tecnologías en el currículum, han obtenido avances más significativos que otros centros que seguían trabajando con un enfoque más tradicional (Asorey y Gil, 2009). 
Según los autores mencionados, la Comunidad Valenciana, y la Comunidad de Aragón son dos de las regiones de España donde más se apuesta por las TIC y muchos de los centros educativos de estas comunidades han equipado sus clases con todo tipo de herramientas tecnológicas, como por ejemplo la PDI, ordenadores o tablets, además de mejorar la formación del profesorado tanto dentro como fuera del aula.

Toda esta innovación en las aulas ha generado que la metodología educativa esté sufriendo un cambio, tal y como expone Gardner (2012) «La irrupción de las nuevas tecnologías nos obliga a educar a los niños de una manera distinta». Los materiales empleados en las clases poco tienen que ver con los utilizados tradicionalmente como son la pizarra y la tiza. Han aparecido todo tipo de estrategias y recursos tecnológicos que han cambiado la manera de ver el aprendizaje educativo, ampliando el abanico de posibles actividades de enseñanza y aprendizaje.

Los últimos estudios del New Media Consortium (NMC), el NMC Horizon Report: 2013 K-12 Edition y el NMC Horizon Report: 2013 Higher Education Edition, destacan diez tecnologías emergentes que afectarán a la educación en los próximos cinco años: computación en la nube, aprendizaje con el móvil, monitorización del aprendizaje, contenido libre (open content), impresiones en 3D, MOOCs (cursos online masivos), laboratorios virtuales y remotos, juegos y "Gamification", utilización de tablets, y tecnología para llevar incorporada en la ropa o en el reloj.

Una de las tendencias más aplicables a la educación es la llamada "Gamification" (gamificación o ludificación). La cual trata sobre el uso de técnicas y dinámicas propias de los juegos y ocio en actividades no del todo recreativas, pretendiendo transformar una actividad, a priori aburrida, en otra motivadora. Para ello se utilizan todo tipo de estrategias, siendo una de éstas la utilización de videojuegos. Ya que se ha comprobado que aunque en el aula escolar se utilicen un tipo de juegos con una herramienta tecnológica, por ejemplo el ordenador, en casa estos alumnos prefieren dedicar más tiempo a las actividades centradas en la consola, que las realizadas en la escuela con dicho ordenador (Padilla, 2012).

En los últimos años se han realizado estudios para utilizar juegos comerciales dentro de las aulas con fines pedagógicos, de forma que este interés que muestran los alumnos favorezca su uso como herramienta educativa. Además se ha creado una gran multitud de juegos que poseen las características de aquellos que no parecen educativos cuando en realidad sí lo están siendo. Algunos de éstos que se pueden incorporar al aula y al hogar son MundoPocoyo y Scribblenauts, entre otros.

Por otro lado, se está potenciando cada vez más la idea de que los propios docentes sean los creadores de sus materiales educativos. Gracias al auge de herramientas y plataformas educativas gratuitas de fácil manejo para un usuario medio, los maestros y maestras se lanzan a producir sus propios materiales y compartirlos con el resto de la comunidad educativa. Como es en el caso de la plantilla "Orla espacial para fin de curso", como puede verse en la figura 1, creada por el blog Actiludis, donde se proponen 
distintos fondos y objetos para crear la orla de clase. Incluso un video tutorial donde explica paso a paso como llevarla a cabo.
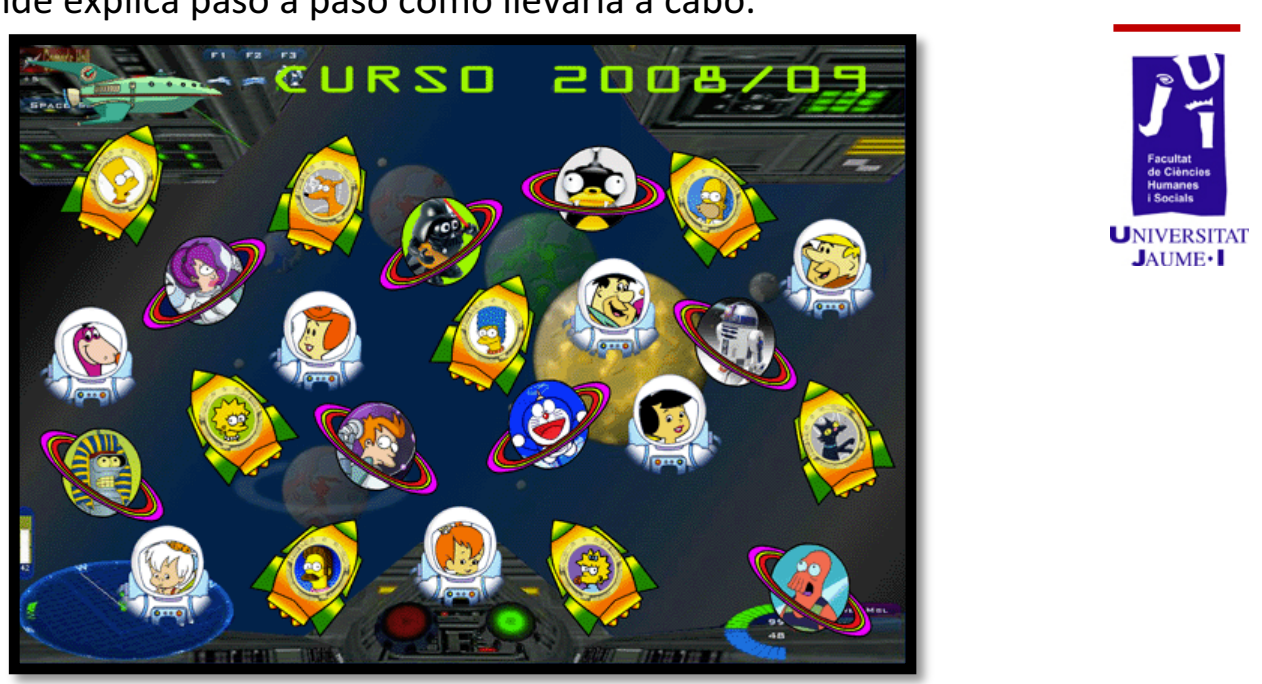

Figura 1. Orla

Por todo lo anteriormente mencionado, en este trabajo se pretende poner en práctica la experiencia de innovar en el aula de educación infantil mediante la creación de un material interactivo, pretendiendo así animar a todos los maestros y maestras a crear sus propios materiales.

\subsection{Tipos de herramientas y recursos más utilizados en el aula}

A continuación se va a realizar una revisión sobre aquellas herramientas tecnológicas que se utilizan en España en las clases de Educación Infantil y de los recursos que derivan de estas. Algunas de las herramientas tecnológicas más utilizadas son:

PDI

La PDI o Pizarra Digital Interactiva es una herramienta muy utilizada últimamente en las clases de Educación Infantil. Normalmente suele llegar al colegio gracias a una editorial, la cual se encarga de que sus libros y actividades puedan realizarse con dicha herramienta. Su uso es táctil y puede ir acompañada de un ordenador que reproduzca el contenido o las búsquedas que se hagan en Internet.

\section{Tablet o tableta}

Es similar a un ordenador portátil, de dimensiones reducidas y táctil. La tablet es muy conocida hoy en día por los niños ya que su uso es muy intuitivo y asequible para estos. Muchos de ellos ya conocen esta herramienta porque disponen de una en casa. Con ella los niños y niñas pueden hacer ejercicios de grafomotricidad, matemáticas, creatividad, destreza lógica... y su uso puede ser tanto individual como colectivo. No muchos de los colegios de España disponen de una o varias tablets en clase, pero su uso es muy conveniente y motivador para el alumnado. El problema es que no se dispone de recursos necesarios para incluir estas tecnologías en todas las aulas. 


\section{Ordenadores}

Actualmente muchas clases de infantil disponen de uno o varios ordenadores en el aula. En ellos se suelen realizar actividades de informática y/o juegos, para introducir el manejo del ordenador desde edades tempranas.

\section{Pizarra con proyector}

Esta herramienta está formada por una pizarra tradicional de tiza, un proyector y un ordenador. La pizarra es de color blanco, pudiendo así proyectar el contenido del ordenador directamente en la pizarra. Si se desea utilizar como una herramienta tradicional, solo es necesario apagar el proyector y utilizar las tizas de colores para escribir en ella.

También existe otro tipo de pizarras blancas en las cuales se puede escribir con rotuladores en lugar de con tizas de colores.

Este tipo de pizarras son muy útiles, ya que se dispone de un material tradicional, pero a su vez se utiliza como un recurso tecnológico innovador. Una de sus múltiples funciones es proyectar los ejercicios que se vayan a hacer en clase, ya sean unos propuestos por la editorial (proyectando la ficha del libro correspondiente) o una actividad creada por los docentes. La ventaja es que pueden salir varios alumnos a escribir en ella a la vez, cosa que con la PDI no se puede hacer (si no es que se dispone de una PDI que permite tener más de un punto de apoyo a la vez). En la Figura 2 aparece una muestra de este recurso utilizado en un aula de Infantil.

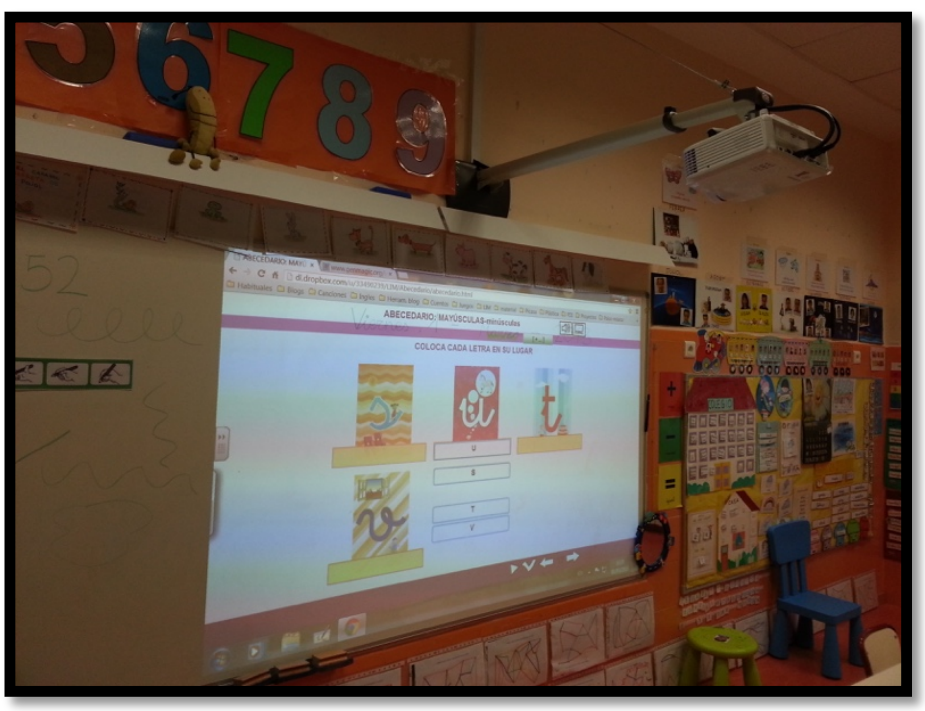

Figura 2. Pizarra

A continuación se incluyen algunos de los recursos a utilizar con las TIC en el aula:

\section{Blog}

La maestra o maestro crea un blog con Google (Blogger) o Wordpress, o cualquier otra plataforma disponible en Internet, donde recoge sus experiencias en el aula. En dicho blog se plasma cómo trabajan los alumnos, qué actividades realizan, muestras de estas actividades, fotografías sobre excursiones y salidas, acontecimientos especiales, cosas 
a destacar, etc. Esta herramienta es ideal para poder mantener un diálogo fluido con las familias, ya que así, éstas pueden tener un seguimiento diario de lo que hacen sus hijos en la escuela. Además, sirve de intercambio de información entre otras maestras, familiares y especialistas de la educación, gracias al traspaso de materiales y conocimientos.

Como ejemplo de este recurso destacan los blogs: "La clase de Miren", "Classe de les girafes" y "Mi cole al día" los cuales tratan sobre las experiencias en el aula de Infantil de varios colegios de España.

\section{JClic o Edilim}

Programas para crear actividades interactivas de tipo lúdico o académico para los alumnos. En este caso el profesor tiene la oportunidad de coger un JClic de un tema ya elaborado por otro docente o crear uno propio. Es una herramienta de manejo fácil tanto para su creación por parte del adulto, como para su uso por parte de los más pequeños.

\section{Storybird}

Plataforma que permite crear historias visuales o cuentos. Dedicada a todo tipo de públicos, tanto a ilustradores profesionales, como a maestros y alumnos. Recurso ideal para los docentes de Infantil que deciden crear un cuento o historia interactiva relacionada con el contenido que se esté llevando a cabo en el aula.

\section{Symbaloo}

Symbaloo es una plataforma que ayuda a organizar contenidos online. Es ideal para maestros y educadores, ya que es una manera fácil de organizar, de un golpe de vista, las actividades o juegos a trabajar en el aula.

En la cuenta de Symbaloo personal o propia se crea una carpeta con todo tipo de enlaces a juegos, blogs, páginas web, etc. Una vez esta carpeta esta abierta y en pantalla, los alumnos proceden a hacer clic sobre el juego o actividad a trabajar.

El uso de esta herramienta en el aula es interesante ya que no es necesario descargar los juegos en el ordenador, estos permanecen en la nube, y mediante el diseño propio del programa se puede acceder a ellos fácilmente, tal y como muestra la Figura 3. 


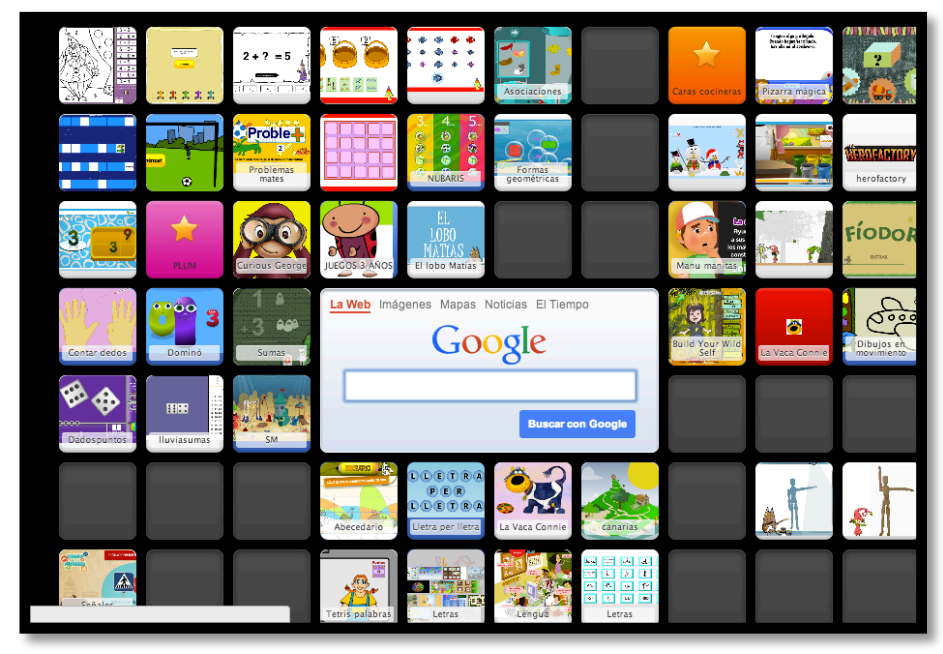

Figura 3. Symbaloo

\section{Make it}

Aplicación, por ahora solo disponible para tabletas Apple, con la cual es posible crear juegos, actividades, cuentos... y poderlos compartir o visualizar en otro soporte, como por ejemplo, un ordenador. Esta herramienta combina distintas plantillas para la creación de juegos y posee un diseño atractivo, además de ser de fácil manejo para cualquier usuario.

En primer lugar, se crea un proyecto nuevo, al que se le da un nombre. Tras esto se puede elegir un tema que predominará en el juego, por ejemplo, "Blue Sky", con el cual aparece un fondo de nubes, el texto y la apariencia en tonos azules. A su vez, es posible definir un tema libre, añadiendo un fondo desde Internet o una imagen al gusto del creador.

Tras esto se procede a la elección de plantillas dinámicas, donde cada una representa una actividad. Algunas de éstas son:

- Conectar: test de relaciones usando conectores.

- Arrastrar a un contenedor: test de relaciones usando contenedores.

- Memoria: realización de parejas.

- Dibujo: pintar y colorear.

- Encontrar: encontrar la respuesta correcta.

- Concurso: preguntas y respuestas de múltiples opciones.

- $A B C$ : crear una pregunta y solicitar una respuesta escrita.

- Texto: páginas libres para añadir cualquier recurso.

Luego de la elección de la actividad se rellena su contenido, añadiendo imágenes, texto, y sonido. Estos se pueden elegir del propio dispositivo o del banco de imágenes y sonido que ofrece Make it.

Una vez finalizada la primera actividad se pueden añadir más hasta terminar el proyecto, el cual se puede previsualizar, viendo el aspecto que tendrá al ser jugado.

Finalmente, dicha actividad lúdica se puede desarrollar en el dispositivo tablet, pero también es posible compartirla por e-mail o por medio de un enlace, con lo cual se puede acceder a ella desde cualquier ordenador, PDI o móvil. 
En los siguientes apartados explicaremos más detalladamente la utilización de este recurso en una clase de Educación Infantil de 5 años.

\section{Objetivos}

Innovar en el aula mediante la creación de un material interactivo.

Mejorar el aprendizaje de contenidos por parte de los alumnos y alumnas.

Animar a los docentes a crear sus propios materiales interactivoseducativos.

Concienciar a los docentes y a las familias de la importancia de las TIC en la educación para mejorar el proceso enseñanza-aprendizaje.

Realizar una revisión de las herramientas TIC utilizadas más frecuentemente en aulas de infantil de colegios de toda España.

Dar una visión general del uso de las TIC en España, así como de las ventajas e inconvenientes de su implementación en el aula.

\section{Material y método}

En este trabajo se ha procedido a la elección de la herramienta tecnológica tablet para su uso en Educación Infantil, debido a que resulta muy atractiva, motivadora, con alta usabilidad y conocida previamente por el alumnado.

Al comienzo del curso se dispone de una editorial que marca los contenidos a trabajar en el aula, según el Decreto 38/2008, de 28 de marzo, por el que se establecen las enseñanzas mínimas del segundo ciclo de Educación Infantil en la Comunidad Valenciana.

En el caso de la clase de 5 años se procede a trabajar la Unidad Didáctica "L'Univers". Esta unidad es elegida específicamente, ya que no solo es un tema atractivo para los estudiantes, sino que además existen abundantes recursos TIC para trabajarlo.

Normalmente en cada Unidad Didáctica se realiza una combinación de actividades ya marcadas por el libro de la editorial y otras externas incluidas por la maestra.

En este caso, el objetivo es incluir además, una serie de actividades utilizando las TIC. Para ello se procederá a un cambio en la metodología y dinámica de la clase. El rincón de informática pasará a estar situado en otro espacio del aula, donde se ubicará la tablet. El alumnado solo podrá hacer uso de ésta en los tiempos acordados y siempre de manera grupal. Se realizará una explicación previa de cómo se debe utilizar dicha herramienta, cuántos de ellos participarán en cada sesión y qué hacer en caso de duda. Esto es necesario ya que los alumnos suelen realizar algunas actividades utilizando la PDI y/o ordenador, pero no con la tablet, con lo cual es importante llevar una buena organización de la clase para que la excitación y nerviosismo no impidan el progreso de la actividad. 


\section{Muestra y sujetos de estudio}

Los sujetos de estudio son 30 alumnos y alumnas (17 niñas y 13 niños), de entre 5 y 6 años de edad, de tercero de Educación Infantil del CEIP Pintor Castell de Castellón.

En la clase se dispone de un ordenador fijo y otro portátil conectado a la PDI y al proyector de ésta.

Estos alumnos ya poseen conocimientos y han mantenido relación con aparatos tecnológicos, debido a que un día a la semana pasan una hora en el aula de informática, donde cada uno de ellos utiliza un ordenador. Además disponen de una PDI en el aula habitual de enseñanza.

\section{Descripción de las actividades complementarias a la Unidad Didáctica}

La Unidad Didáctica 9 "L'Univers" del Projecte Bub-bub SM, Comunitat Valenciana (González de la Torre y Gimeno, 2013) que sigue el Ciclo de Infantil, hace una pequeña aproximación al conocimiento del espacio en general, haciendo hincapié en el concepto de estrellas, planetas, movimientos de la Tierra, el día y la noche, las estaciones del año, entre otros.

Es un tema muy motivador y atrayente para los alumnos, lo cual permite que estos se impliquen al máximo. A su vez, Internet está repleto de recursos interactivos e ideas TIC para ampliar dicha unidad.

\section{Objetivos, contenidos y competencias}

Objetivos, contenidos y competencias a trabajar durante la Unidad Didáctica respecto a los materiales TIC diseñados.

\section{Objetivos}

Disfrutar con el manejo de las TIC.

Practicar la habilidad de desplazar el dedo por la pantalla.

Utilizar los recursos informáticos para crear, reproducir, comunicar y conocer.

\section{Contenidos}

La pantalla táctil.

Utilización de los recursos informáticos para realizar nuevas creaciones.

Valoración de las TIC como un medio de comunicación y aprendizaje.

\section{Competencias}

Competencia en el conocimiento y la interacción con el mundo físico. Uso de herramientas tecnológicas: Hacer uso habitual de los recursos tecnológicos para aplicarlos en diversos entornos y resolver problemas reales.

Tratamiento de la información y competencia digital: El uso de las funciones más elementales de la tablet adecuadas a la edad, como abrir y cerrar la aplicación, pintar un dibujo, pasar página, encender y apagar el dispositivo, etc. 
Actividades

Rincones

Por las tardes los alumnos trabajan por rincones. «Lugar, permanente o no, en el que se desarrollan actividades muy determinadas, libres o dirigidas, individuales, en grupos pequeños o colectivos: biblioteca, grafismo, cocina, tienda, muñecas, garaje, etc.» (Tavernier, R., 2987:191)

En este caso en concreto, los rincones son zonas de trabajo ubicadas en el propio aula, donde el alumnado trabaja una actividad en grupo de forma autónoma, sin ayuda del docente.

La clase está formada por 6 rincones, al igual que 6 grupos de alumnos componen el aula:

1. Rincón de matemáticas: ejercicios de sumas y restas relacionados con el espacio.

2. Rincón del mural: construcción de un mural del espacio.

3. Rincón del modelaje: creación de imanes de nevera con plastilina (extraterrestres, planetas, estrellas...)

4. Rincón de manualidades: construcción de un móvil del espacio.

5. Rincón de informática: juegos interactivos relacionados con el espacio.

6. Rincón de la biblioteca: ordenar palabras para formas frases y lectura de libros y/o cuentos relacionados con el espacio.

Los 6 grupos de alumnos van rotando cada día por cada rincón. Estos grupos están formados por 4 ó 5 alumnos. Los días destinados a rincones son los lunes, martes y jueves. El primer día de la semana, se explica en qué consiste cada rincón y cómo se debe trabajar en él. Una vez entendidas las normas, los niños trabajan autónomamente, siendo el papel de la maestra el de ayuda o apoyo.

El presente trabajo se centra sobretodo en las actividades del rincón de informática, aunque a su vez se utilizarán recursos TIC durante toda la jornada escolar; como es el uso de la PDI mientras realizan las fichas correspondientes a la unidad, búsqueda de fotos y vídeos para hacer aclaraciones, etc.

\section{El rincón de informática}

Este rincón se distribuye en dos espacios del aula. Uno de ellos donde está ubicado el ordenador de sobremesa, al final de la clase; y el otro espacio junto a la PDI. En este caso, ambos espacios no formarán parte del estudio, ya que nos centraremos en el juego interactivo que se utilizará en la tablet, siendo el lugar destinado para ello las mesas de clase.

Make it

El programa Make it explicado anteriormente, solo está disponible para tabletas Apple, pero las actividades creadas en ésta pueden utilizarse en cualquier dispositivo, como por ejemplo en un ordenador, la PDI, un móvil, a través de Internet. En este caso, se realizarán las actividades en la tablet. 
Una vez abierto el proyecto "L'Univers" creado con la aplicación, el grupo de alumnos compuesto por 5 niños y/o niñas, se organiza para jugar por turnos. Cada álbum de juego está compuesto por varias actividades. Si la actividad da error, los niños deberán intentarlo de nuevo. Si por el contrario se celebra el triunfo del jugador, podrán pasar a la siguiente tarea.

Una pequeña muestra de las actividades realizadas con este recurso son:

Actividad 1: Unión de imágenes y palabras

El objetivo de esta actividad es el de unir una imagen con la palabra correspondiente. Aparecen varias imágenes de planetas a la derecha de la pantalla y sus nombres a la izquierda. Los alumnos deben unir cada planeta con su nombre adecuado, arrastrando el dedo por la pantalla.

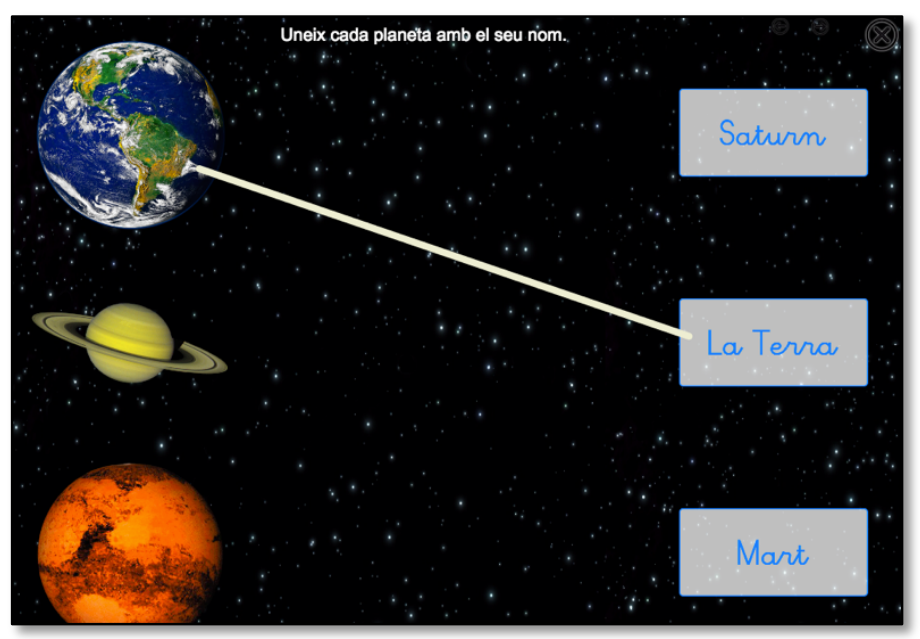

Figura 4. Unión de imágenes y palabras

\section{Actividad 2: Memory}

Aparecen en la pantalla varias cartas boca abajo, de manera que no se ve el contenido de estas. El alumno debe pulsar sobre dos cartas. Si las dos cartas tienen la misma figura permanecerán giradas, ha conseguido una pareja. Si por el contrario, son distintas se volverán a dar la vuelta. El objetivo es memorizar en qué lugar está cada carta e intentar hacer el máximo de parejas posible. Finalmente se gana cuando están todas las cartas giradas. Las imágenes que aparecen en las cartas están relacionadas con el universo, como: planetas, astronautas, estrellas, extraterrestres, etc. Un ejemplo de esta actividad aparece a continuación en la Figura 5. 


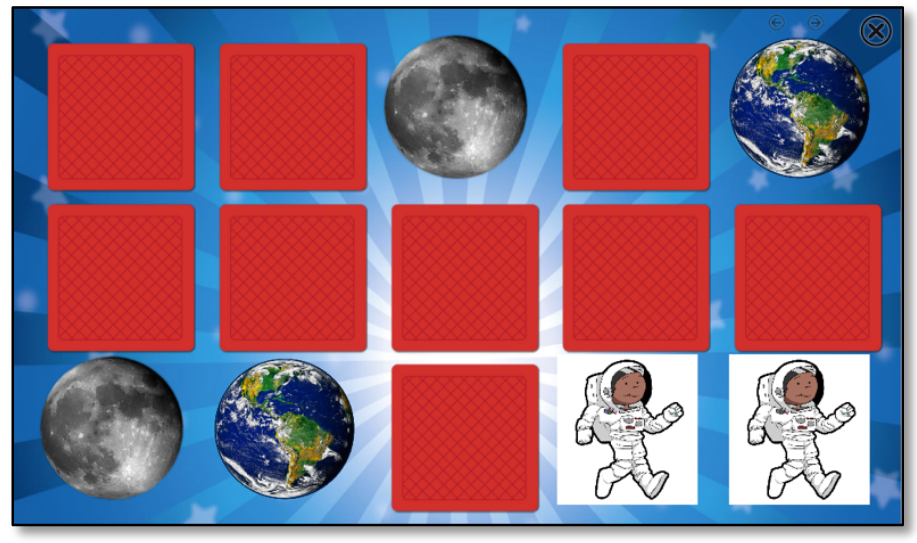

Figura 5. Memory

\section{Actividad 3: Colorear}

En esta actividad se ha de colorear un planeta. Este está en blanco y negro, así que los alumnos deben elegir un color de la platilla de colores y un grosor de pincel. Tras esto se procede a colorear el dibujo, cambiando de color y pincel las veces que se desee.

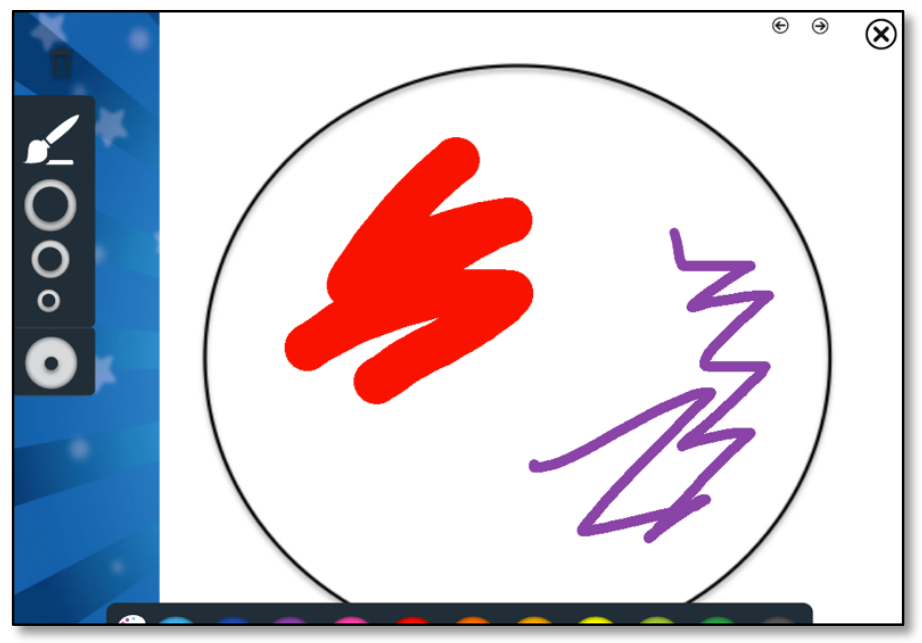

Figura 6. Colorear

\section{Actividad 4: La lupa}

En la pantalla aparecen varios elementos relacionados con el espacio, como: un astronauta, una nave espacial, planetas, estrellas, etc. En la parte inferior de esta hay una lupa que muestra uno de los objetos de los nombrados anteriormente. Los jugadores han de ser capaces de identificar el objeto que muestra la lupa, buscarlo entre todos los demás y pulsarlo. Tras esto se procede a la búsqueda de un nuevo objeto hasta que estén todos encontrados. 


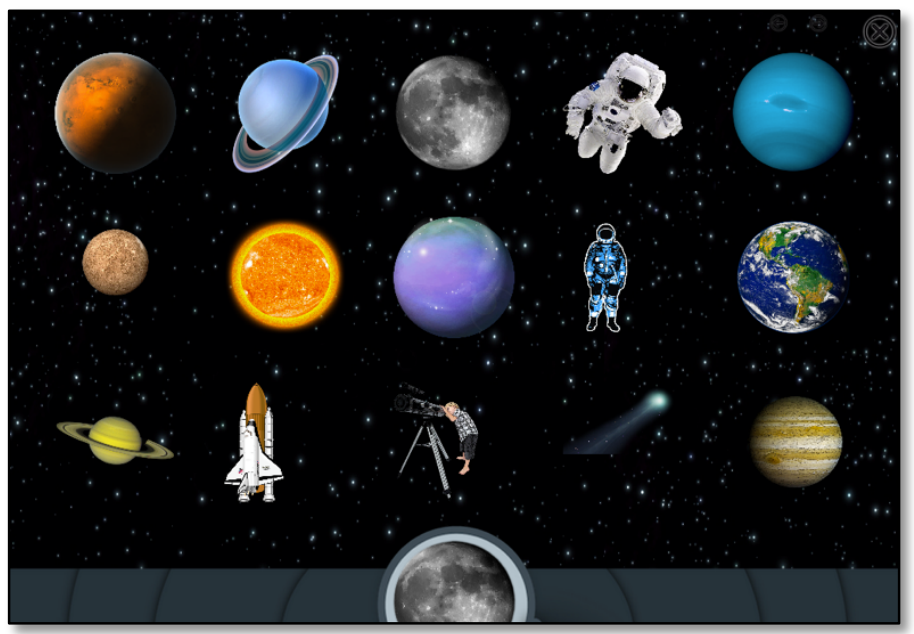

Figura 7. La lupa

Actividad 5: La palabra correcta

Esta actividad consiste en escribir correctamente el nombre de los planetas que aparecen en pantalla. Por ejemplo, aparece una imagen de la Tierra y debajo de esta seis líneas o huecos para escribir. Los alumnos han de ser capaces de identificar el planeta y escribir el nombre de éste, pulsando sobre las letras adecuadas. Cada espacio corresponde a una única letra.

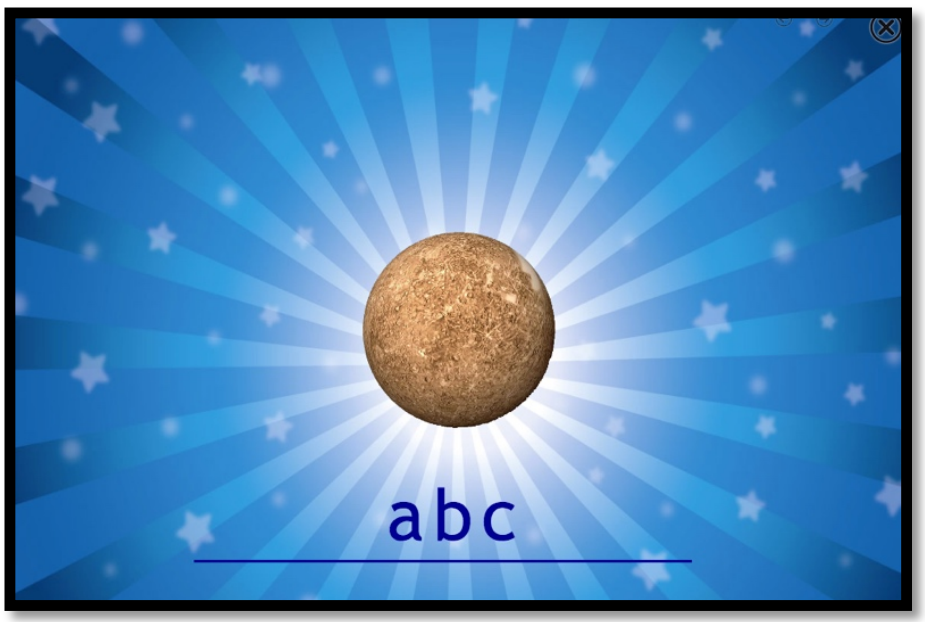

Figura 8. La palabra correcta

\section{Temporalización}

La duración de la Unidad Didáctica "L'Univers" es de aproximadamente 3 semanas, comenzando el lunes 28 de abril y finalizando el viernes 16 de mayo. Para trabajar mediante juego por rincones, se estableció la última media hora del lunes, martes y jueves (16:00 a 16:30). 


\section{Recogida de información}

En primer lugar se procederá a realizar una evaluación diagnóstica del alumnado, para determinar qué conocimientos previos poseen sobre "L'Univers". Para conseguir esta información es necesario crear un ambiente de diálogo y participación. Tras esto se evalúa las potencialidades y dificultades de los alumnos ante el temario; también llamada evaluación procesual. Y por último la evaluación final, que consiste en la realización de un informe global sobre la trayectoria del alumno, y propuestas de mejora en cuanto a la metodología o problemas que hayan surgido ante la adquisición de conocimientos por parte del alumnado.

Dicha evaluación final de toda la unidad se plasma en unos cuadros evaluativos proporcionados por la editorial, donde se recogen los ítems a adquirir por los alumnos. Estos ítems serán valorados por la docente, quien determinará cuáles han sido trabajados o son adecuados para la realidad del aula.

Por otro lado, se realizará una pequeña evaluación sobre la implantación de esta nueva herramienta TIC, la tablet, en el temario. Para así comprobar si su uso ha mejorado los conocimientos del alumnado, solo los ha reforzado, ha sido un impedimento para estos, etc. Para ello se hará uso de la observación participante, las anotaciones pertinentes en el cuaderno de la docente y la prueba oral objetiva; donde se pregunta de forma individual a cada alumno qué ha aprendido a lo largo de esta Unidad Didáctica, si recuerda el nombre de algún planeta del Sistema Solar, si sabe qué es un astronauta y algunas de las partes del traje de este, etc.

A continuación se muestra una serie de ítems a evaluar según el material educativo innovador que se ha procedido a integrar en el aula:

- Disfruta con el uso de las TIC.

- Practica de manera adecuada la habilidad de desplazar el dedo por la pantalla.

- Utiliza los recursos informáticos para crear, reproducir, comunicar y conocer.

\section{Resultados}

El uso de la tablet como complemento TIC a la Unidad Didáctica ha sido todo un éxito y se han cumplido los objetivos de evaluación.

En primer lugar, el alumnado ha aprendido de una manera más motivadora y lúdica los conceptos tratados durante las sesiones, recordando nombres de planetas, vehículos para ir al espacio, instrumentos como el telescopio, el primer ser vivo que viajó a la Luna, etc. A su vez, aquellos conocimientos que para algunos eran confusos se han reforzado y afianzado mediante el juego.

Es importante destacar el juego en equipo, es decir, los niños y niñas han aprendido a esperar su turno, a dialogar sobre la respuesta correcta, a respetar las decisiones de otro compañero y en definitiva, a trabajar de forma cooperativa. Esto es vital, ya que cada individuo aprende más de lo 
que aprendería por sí solo, fruto de la interacción de los integrantes del equipo.

Es necesario remarcar que la clase no tuvo ninguna dificultad en manejar esta herramienta, ya que casi todos conocían su funcionamiento por poseer una igual o parecida en casa. Además de tener en cuenta que el manejo de ésta es muy intuitivo para los pequeños, ya que su uso se realiza con los dedos, arrastrando o apretando, con lo cual no deben tener apenas dificultad a la hora de utilizar la psicomotricidad fina necesaria para ello.

Por otro lado, la creación de esta herramienta requiere conocimientos digitales por parte del docente, además de poseer éste $u$ otro dispositivo tecnológico y tiempo para llevarla a cabo; incluyendo la búsqueda de imágenes adecuadas al temario tratado en el aula, diseño de cada actividad que aparece en el juego, inclusión de sonidos, jugabilidad, etc.

A su vez, en todo momento se refuerza la idea de tratar de manera adecuada la tablet, corriendo el riesgo de que se produzcan accidentes 0 golpes inesperados.

Por todo ello, es posible destacar una serie de ventajas e inconvenientes ante la utilización, creación y aplicación directa en el aula de estas nuevas herramientas.

Ventajas

- Motivación y predisposición al aprendizaje.

- Aumento de la participación.

- Desarrollo de la creatividad.

- Aprendizaje cooperativo y trabajo individualizado.

- Desarrollo de las destrezas necesarias para la utilización de las TIC (competencia digital).

- No dependencia total de las editoriales.

- Compartir recursos con el resto de la comunidad educativa.

- Utilización de diferentes medios: texto, imagen, sonido, vídeo, voz, etc.

- Rápida asimilación de contenidos.

\section{Inconvenientes}

- Es necesario el conocimiento de las TIC por parte del profesorado.

- Necesaria una buena educación y uso responsable de estas por parte de los alumnos.

- Falta de dotación económica y/o material en las aulas.

- Tiempo dedicado a la búsqueda y/o creación de materiales interactivos.

- Dispersión de la información debido a la gran cantidad de contenidos en red.

- Problemas asociados a dichas herramientas (cuelgue del ordenador, falta de conexión a Internet, etc.) 
Como conclusión decir que se han cumplido los objetivos marcados por esta Unidad Didáctica gracias a la combinación de las actividades tradicionales y el juego innovador de la tablet. La gran mayoría de los alumnos ha superado los ítems marcados, tanto los conceptos del Universo, como la adecuada utilización y disfrute de dicha herramienta.

Estos resultados concuerdan con las teorías y opiniones de los investigadores y teóricos como Robinson (2006, 2013), o Carr-Chellman (2010), entre otros; respecto a que las nuevas tecnologías complementan las herramientas tradicionales de la educación, produciendo así una mejora educativa. Además de la gran motivación que el uso de estos aparatos representa para el alumnado, haciendo que la asimilación de conceptos sea mayor y se produzca el aprendizaje, de una manera lúdica y amena.

La experiencia de crear un juego para la tablet potencia las habilidades del docente, acercando a este a la era digital y pudiendo así adecuar los contenidos a la realidad del aula, dejando al margen las editoriales y contribuyendo al intercambio de recursos educativos entre maestros, vía Internet.

Como propuesta de mejora añadir que es necesaria una mayor formación del profesorado en las nuevas tecnologías para que haya continuidad en las actividades y este tipo de propuestas no se queden en lo anecdótico. Es preciso que desaparezca la brecha digital que existe entre algunos alumnos y profesores, ya que las TIC forman parte del día a día. Además del cambio de pensamiento respecto a los juegos y videojuegos, dejando a un lado los mitos asociados a estos, aceptando que pueden contribuir a mejorar la educación y formar parte de esta.

A su vez, invitar a todos los profesores y futuros docentes a innovar y realizar sus propias creaciones de actividades y/o juegos. Ya que en determinadas ocasiones se pasa mucho tiempo en Internet buscando recursos didácticos relacionados con una materia en concreto, intentando que a su vez sean motivadoras e interesantes para el aula, y al final estas no acaban adaptándose a los objetivos o la idea que se tiene en mente para plantear las actividades. La elaboración de actividades educativas propias enriquece el aporte de materiales TIC útiles para las clases y además permite reflexionar sobre si los contenidos trabajados en el aula son los más adecuados, es decir, permite una autoevaluación o autocrítica de la práctica docente.

Como reflexión final destacar una cita de Williams, donde el cual remarca: «El futuro de la educación estará profundamente ligado a la tecnología de la información venidera. Pero más aún, por cómo los educadores y estudiantes utilizan las TIC para el aprendizaje continuo» (Williams, 2002). 
Asorey, E. y J. GIL (2009): El placer de usar las TIC en el aula de Infantil. Tribuna abierta. CEE Participación Educativa.

CARR-Chellman, A. (2010): Gaming to re-engage boys in learning.

Recuperado de

https://www.ted.com/talks/ali_carr_chellman_gaming_to_re_engage_bo

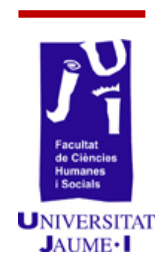
ys in learning

EsteVE, F. (2009): Bolonia y las TIC: de la docencia 1.0 al aprendizaje 2.0. La cuestión universitaria, 5, 59-68.

GARDNER (2012): De las inteligencias múltiples a la educación personalizada. Redes. RTVE. Recuperado de http://www.rtve.es/alacarta/videos/redes/redes-inteligencias-multipleseducacion-personalizada-vo/1270214/

GonzÁlez de la ToRre, P. y Gimeno, E. (2013) Bub-bub 5 anys, SM, Comunitat Valenciana.

GVA (2008): DECRETO 38/2008, de 28 de marzo, del Consell, por el que se establece el currículo del segundo ciclo de la Educación Infantil en la Comunitat Valenciana. [2008/3838]. Recuperado de http://www.docv.gva.es/datos/2008/04/03/pdf/2008_3838.pdf

LA FACTORIA INTERACTIVA. Make it. Recuperado de https://itunes.apple.com/us/app/make-it-create-share your/id 803818300 ? l=ca\&ls $=1 \& \mathrm{mt}=8$

LAz, M.J. (2011): "Nuevas Tecnologías aplicadas a la educación". Recuperado de http://www.csif.es/archivos/andalucia/ensenanza/revistas/iee/Numero_44/MANUEL_JE SUS_LAZ_1.pdf

MARCHAL, E. (2010): IV Jornada de Formación e Innovación educativa. Recuperado de http://www.slideshare.net/espemarchal/iv-jornadas-deformacin-e-innovacin-educativa-5696444

MARQUÉs, P. (2008): La magia de la pizarra digital... la pones tu.

Recuperado de http://www.peremarques.net/docs/ppmagiapizarradigital.ppt

MARTín, N. (Blog Internet). Mi cole al día. Recuperado de http://micolealdia.blogspot.com.es/

Ministerio de EdUCACIÓn Y CIENCIA (2006): Ley Orgánica 2/2006, de 3 de mayo, de Educación. BOE no106, de 4 de mayo, 17158-17207.

Ministerio de IndUStRIA, Energía y TURISMo (2010). Plan Avanza. Estrategia 2006-2010. Recuperado de https://www.planavanza.es/informaciongeneral/estrategia2011/Paginas/ Estrategia2011_2015.aspx 
Ministerio de IndustriA, Energía y TURISMo (2010). Plan Avanza2. Estrategia 2011-2015. Recuperado de

https://www.planavanza.es/informaciongeneral/estrategia2011/Paginas/

Estrategia2011_2015.aspx

MundoPocoyo. Pocoyo ${ }^{\text {TM }}$ \& (C) 2005 - 2014 Zinkia Entertainment, S.A.

"Mundo Pocoyo" тм \& (c) 2009 - 2014 Zinkia Entertainment, S.A.

Recuperado de http://www.pocoyo.com/mundopocoyo\#

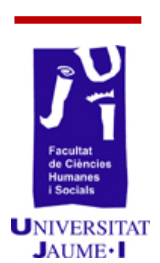

PAdilla, N. (2012): El uso educativo de los videojuegos. Junta de Andalucia. Consejería de Educación. Recuperado de http://www.juntadeandalucia.es/educacion/webportal/descargas/familia s-lectoras/flash/coleccion/resources/cariboost files/cuaderno09.pdf

PARDO, M. (Blog Internet). La clase de Miren: mis experiencias en el aula. Recuperado de http://laclasedemiren.blogspot.com.es/

RoBINSON, K. (2013): Las tecnologías pueden ayudar a revolucionar la educación. Recuperado de http://blog.tiching.com/sir-ken-robinson-lastecnologias-pueden-ayudar-revolucionar-la-educacion/

RoBINSON, K. (2006): How schools kill creativity. Recuperado de https://www.ted.com/playlists/24/re_imagining_school

SCRIBBLENAUTS .5th Cell. WB Games. Recuperado de http://www.scribblenauts.com/scribblenauts/unmasked/en_US/about\#

STORYBIRD. Recuperado de http://www.storybird.com/

SymbalooEdu. Recuperado de http://www.symbalooedu.es

TAVERNIER, R. (2987:191). Recuperado de http://www.slideshare.net/Gemuchi/presentacin1-5757288

THE NEW MEDIA CONSORTIUM (NMC) (2013): 10 Emerging Educational Technologies \& How They Are Being Used Across the Globe. Recuperado de http://www.innovationexcellence.com/blog/2013/07/29/10emerging-educational-technologies-how-they-are-being-used-across-theglobe/

WiLLIAMS, S. (2002): «Future of education = Technology + Teacher». In Visions 2020: Transforming Education and Training Through Advanced Technologies, pp. 65-68. 